\title{
Neonatal mortality in a referral hospital in Cameroon over a seven year period: trends, associated factors and causes.
}

\author{
Mah Mungyeh E ${ }^{1}$, Chiabi A ${ }^{1}$, Tchokoteu Pouasse FL ${ }^{1}$, Nguefack $\mathrm{S}^{1}$, Bogne JB ${ }^{2}$, Siyou $\mathrm{H}^{2}$, Soh Fru F², Mbonda E , \\ Tchokoteu PF ${ }^{1}$
}

1. Faculty of Medicine and Biomedical Sciences, University of Yaounde I/Yaounde Gynaeco-Obstetric and Pediatric Hospital, Cameroon

2. Yaounde Gynaeco-Obstetric and Pediatric Hospital, Cameroon

\begin{abstract}
Background: The fourth Millennium Development Goals targets reduction of the mortality rate of under-fives by $2 / 3$ by the year 2015. This reduction starts with that of neonatal mortality representing $40 \%$ of childhood mortality. In Cameroon neonatal mortality was 31\% in 2011.

Objectives: We assessed the trends, associated factors and causes of neonatal deaths at the Yaounde Gynaeco-Obstetric and Pediatric Hospital.

Methods: The study was a retrospective chart review. Data was collected from the hospital records, and included both maternal and neonatal variables from $1^{\text {st }}$ January 2004 to $31^{\text {st }}$ December 2010.

Results: The neonatal mortality was $10 \%$. Out-borns represented $49.3 \%$ of the deceased neonates with $11.3 \%$ born at home. The neonatal mortality rate followed a downward trend dropping from $12.4 \%$ in 2004 to $7.2 \%$ in 2010 . The major causes of deaths were: neonatal sepsis $(37.85 \%)$, prematurity $(31.26 \%)$, birth asphyxia $(16 \%)$, and congenital malformations $(10.54 \%)$. Most $(74.2 \%)$ of the deaths occurred within the first week with $35 \%$ occurring within 24 hours of life. Mortality was higher in neonates with birth weight less than $2500 \mathrm{~g}$ and a gestational age of less than 37 weeks. In the mothers, it was high in single parenthood, primiparous and in housewives and students..
\end{abstract}

Conclusion: There has been a steady decline of neonatal mortality since 2004.

Neonatal sepsis, prematurity, birth asphyxia and congenital malformations were the major causes of neonatal deaths. Neonatal sepsis remained constant although at lower rates over the study period.

Key words: mortality, neonates, referral hospital, Cameroon

DOI: http://dx.doi.org/10.4314/ahs.v14i3.4

\section{Introduction}

Every year nearly $40 \%$ of all under-five child deaths are newborn babies in their first 28 days of life or the neonatal period. Three quarters of all newborn deaths occur in the first week of life, and between $25 \%$ and $45 \%$ occur within the first 24 hours ${ }^{1}$. One of the eight millennium development goals (MDGs) fixed by the United Nations in 2005, was to reduce the mortality

\section{*Corresponding author: \\ Evelyn Mungyeh Mah \\ Faculty of Medicine and \\ Biomedical Sciences, University \\ of Yaounde I, \\ Yaounde Gynaeco-Obstetric and \\ Pediatric Hospital, Cameroon \\ Tel: +23797984822 \\ E mail: aminevelyn@yahoo.co.uk}

rate of children under five by $2 / 3$ by the year $2015 .^{2}$ Such reduction can only be possible through the reduction of neonatal mortality which represents up to $40 \%$ of infantile deaths. The majority of newborn deaths occur in developing countries where access to health care is low. Most of these newborns die at home, without skilled care that could greatly increase their chances for survival ${ }^{3,4}$.

The gap between developed and developing countries as concerns neonatal mortality remains large. A child born in a developing country is 14 times more likely to die during the first 28days of life than a baby born in a developed country; with sub-Saharan Africa and South East Asia carrying the heaviest portions in terms of global neonatal mortality rates ${ }^{5}$.

According to the Demographic Health Surveys of $2004,{ }^{6}$ and $2011^{7}$, the neonatal mortality rates in Cameroon were 29 per 1000 live births, and 31 per 1000 live births respectively.

The neonatal mortality rate being an indicator of the quality of the obstetrical and neonatal care in a setting, its evaluation permits the estimation of the quality of 
care ${ }^{4,5}$. The evaluation of the efficacy of preventive measures put into place for the reduction of infant mortality can be done through the evaluation of the neonatal mortality rate over a period of time ${ }^{4}$.

Considering that neonatal mortality rates reflect the quality of obstetrical and neonatal care given to patients in a setting we found it necessary to study this mortality in the Yaounde Gynaeco-Obstetric and Pediatric Hospital (a tertiary hospital in Cameroon, and a reference centre for mother and child care) over a seven year period from 2004 to 2010. The aim of this study was to assess the trends, associated factors and causes of these deaths which will guide interventions to improve outcome.

\section{Methods}

Study setting: It was a retrospective, descriptive study covering a period of seven years extending from January 2004 to December 2010 at the neonatology unit of the Yaounde Gynaeco-Obstetric and Pediatric Hospital (YGOPH), which is one of the reference health facilities for mother and child health care in Yaounde, the political capital of Cameroon. It receives patients from Yaounde and other parts of Cameroon, and admissions have increased over the years with the extension of the unit.

The neonatology unit is divided into two sections; one section for preterm infants with 12 incubators and the other section for term neonates with a capacity of 16 cots. The service is taken care of by 2 pediatricians, 1 general practitioner, and 22 nurses together with about 4 auxiliary staff. It receives patients from all over the national territory and the center region in particular.

Inclusion and exclusion criteria: The admission

Table 1: Socio-demographic factors of mothers

\begin{tabular}{lcc}
\hline Variables & Number & Percentage \\
\hline Age & 232 & 42.69 \\
$<20$ years & 232 & 43.69 \\
$20-30$ years & 67 & 12.60 \\
$>30$ years & 369 & \\
Matrimonial status & 162 & 70 \\
Single & & 30 \\
Married & 413 & 77.8 \\
Profession & 70 & 13.2 \\
Students/house wives & 48 & 9.0 \\
Liberal profession* & & \\
Income earners & &
\end{tabular}

*lawyers, traders, hair dressers, tailors etc files of all new borns (in-borns and out-borns) who were hospitalized and died in the unit during the study period were studied. The following data was noted: Sex, gestational age, birth weight, place of birth, postnatal age at the time of death, and the final diagnosis retained at the time of death. The maternal variables studied were: age, marital status, parity and prenatal visits.

All neonates who died on arrival or with empty or incomplete files were excluded from the study. We defined in-hospital neonatal mortality rate as the number of deaths occurring among admitted sick neonates over a given period expressed as a percentage ${ }^{4}$.

Specific mortality rate was defined as the number of neonates who died from a particular pathology divided by the number of neonates admitted for that pathology over a given period ${ }^{4}$.

Data analysis: The data obtained was analyzed with the SPSS17.0 and Excel 2007 soft ware. The results were expressed as percentages and averages. The Chi-squared test was used when necessary to assess significance and statistical significance was at a $\mathrm{P}$ value less than 0.05 .

Ethical considerations: Authorization to carry out the study, and ethical clearance were obtained from the hospital authorities and the hospital ethics committee.

\section{Results}

Mothers' socio-demographic profile: Most of the mothers were at least 30 years of age; with a mean age of 25.38 years (extremes 14-45years); $70 \%$ were single, and about $78 \%$ were students and housewives (Table 1). 
Parity: Mortality was higher in neonates born of primiparous women $(54 \%)$ against $46 \%$ in multiparous women. Concerning prenatal visits, only $25.8 \%$ of the mothers had had at least 4 prenatal visits.

Characteristics of the neonates: There were 5828 neonates hospitalized in the neonatal care unit of the YGOPH over the study period; 583 died giving a mortality of $10 \%$. Some 52 files of deceased neonates were excluded because they had incomplete information and could not be exploited, so we finally analyzed 531 records. Out- borns represented $49.3 \%$ of the deceased neonates with $11.3 \%$ born at home.

The sex distribution of the deceased neonates was 297 males and 232 females giving a sex ratio of 1.27 . Concerning gestational ages, $62.43 \%$ were born at less than 37 weeks gestation; whereas $64.32 \%$ had low birth weights (<2500gms).

Neonates with birth weight less than $2500 \mathrm{~g}$ and a gestational age less 37 weeks had a significantly higher mortality compared to those delivered at term and with normal birth weights. (Table 2).

Table 2: Neonatal mortality as a function of birth weight and gestational age $(\mathrm{N}=527)$

\begin{tabular}{|c|c|c|c|c|c|}
\hline $\begin{array}{l}\text { Birth weight } \\
\text { Gestational } \\
\text { age }\end{array}$ & $<2500 \mathrm{~g}$ & $2500-4000 \mathrm{~g}$ & $>4000 \mathrm{~g}$ & Total & $\%$ \\
\hline $\begin{array}{l}>37 \text { weeks } \\
>37 \text { weeks }\end{array}$ & $\begin{array}{l}307 \\
32\end{array}$ & $\begin{array}{l}21 \\
156\end{array}$ & 10 & $\begin{array}{l}329 \\
198\end{array}$ & 62.43 \\
\hline Total $(\%)$ & $339(64.32)$ & $177(33.59)$ & $11(2.09)$ & $527(100)$ & 100 \\
\hline
\end{tabular}

Causes of deaths: The main causes of deaths were: neonatal infections $(37.85 \%)$, prematurity $(31.56 \%)$, neonatal asphyxia (16\%), and congenital malformations $(10.54 \%)$ (Figure1). Amongst the neonatal infections were 3 cases of neonatal tetanus.

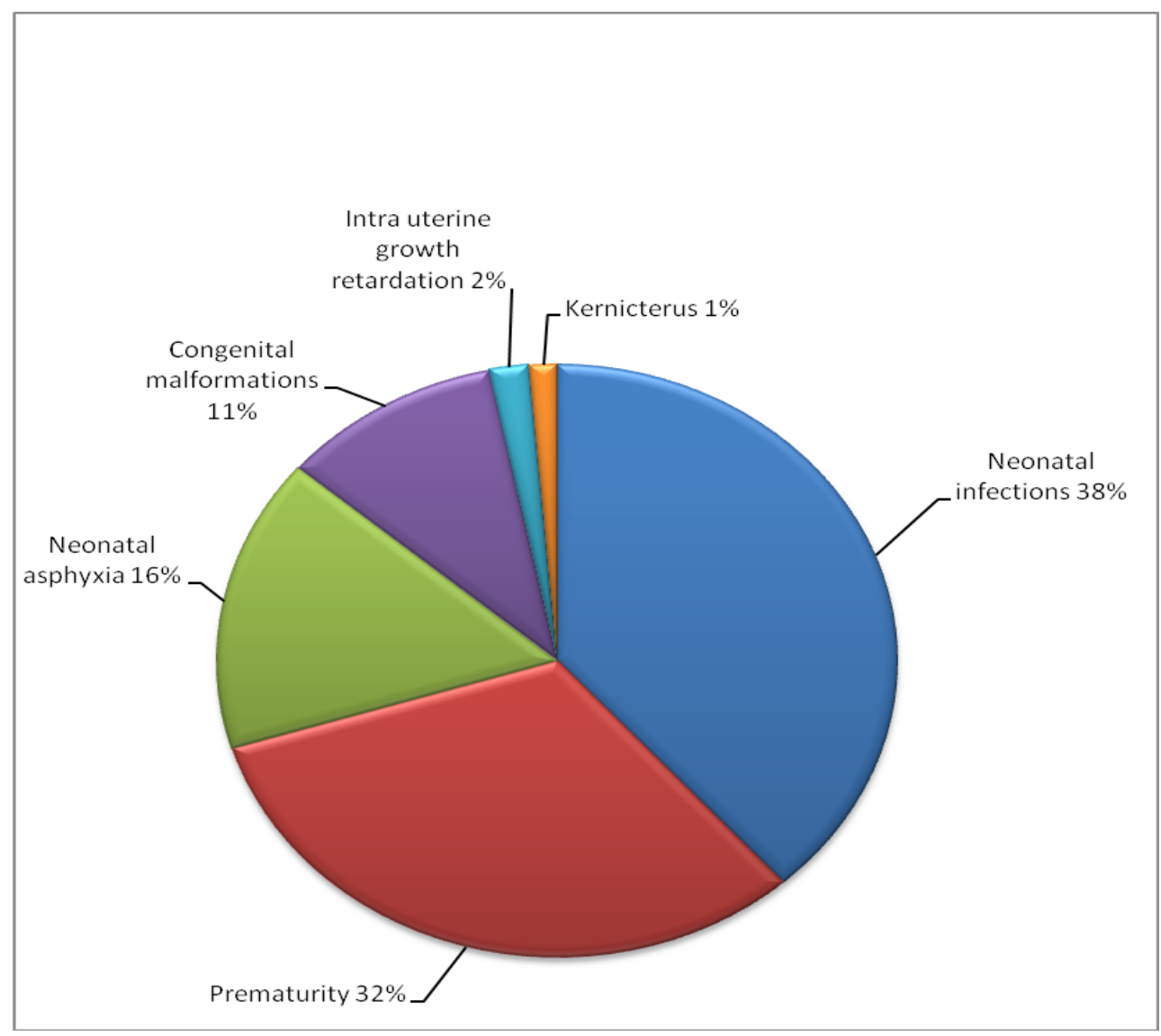

Figure 1. Causes of deaths 
The most frequent congenital malformations were digestive tract obstruction, abdominal wall defects and spina bifida (Figure 2).

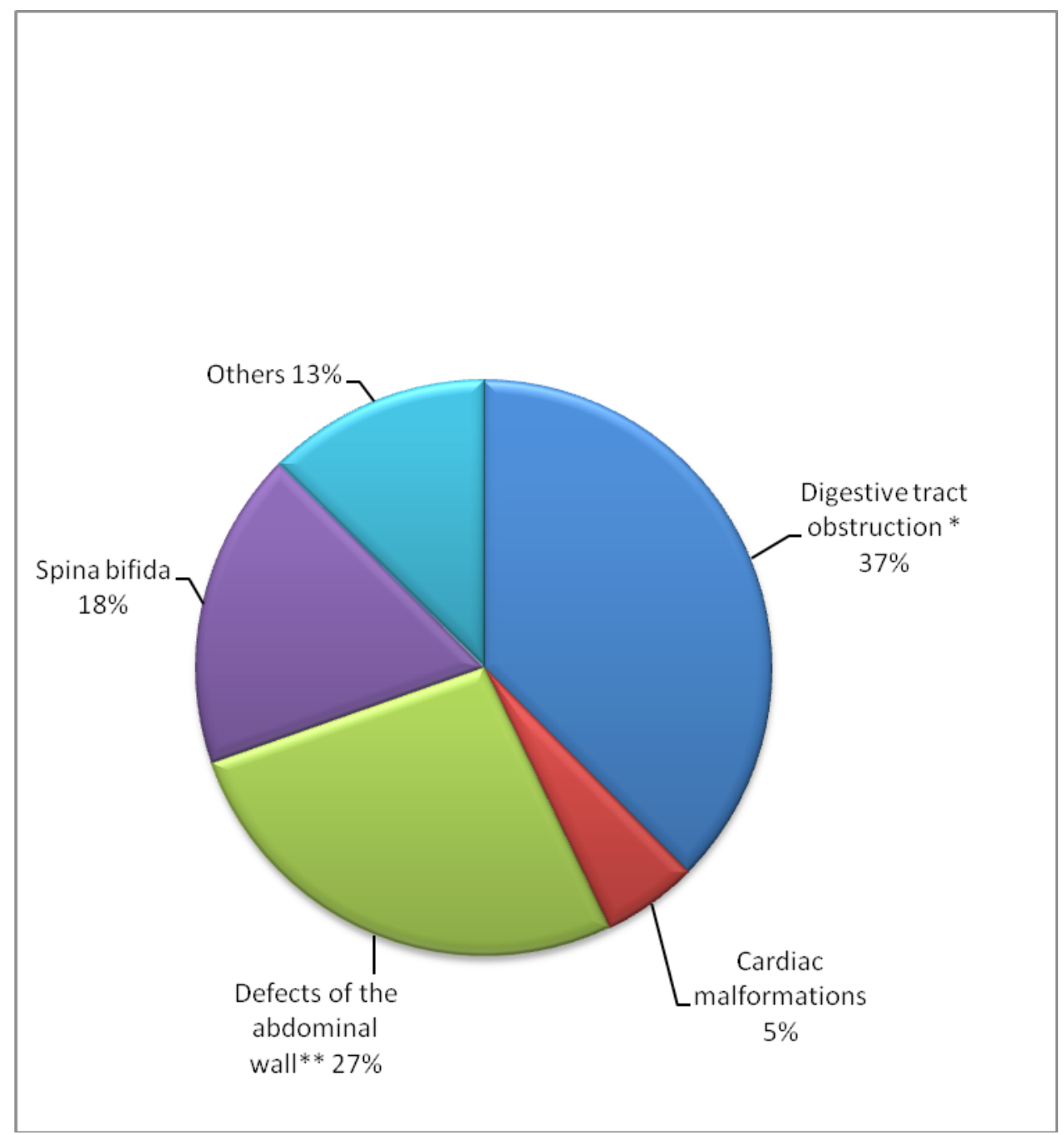

Figure 2: Types of congenital malformations $(\mathrm{N}=56)$

*: duodenal atresia, anal imperforation, oesophageal atresia, intestinal obstruction.

** : laparoschisis, omphalocele...

We noted that $74.2 \%$ of the deaths occurred within the first week, with $35 \%$ occurring within the first 24 hours of life.
Mortality trends: The neonatal mortality rate followed a steady downward trend from 2004 to 2010 with a slight increase in 2008 (Figure 3). 
Percentage

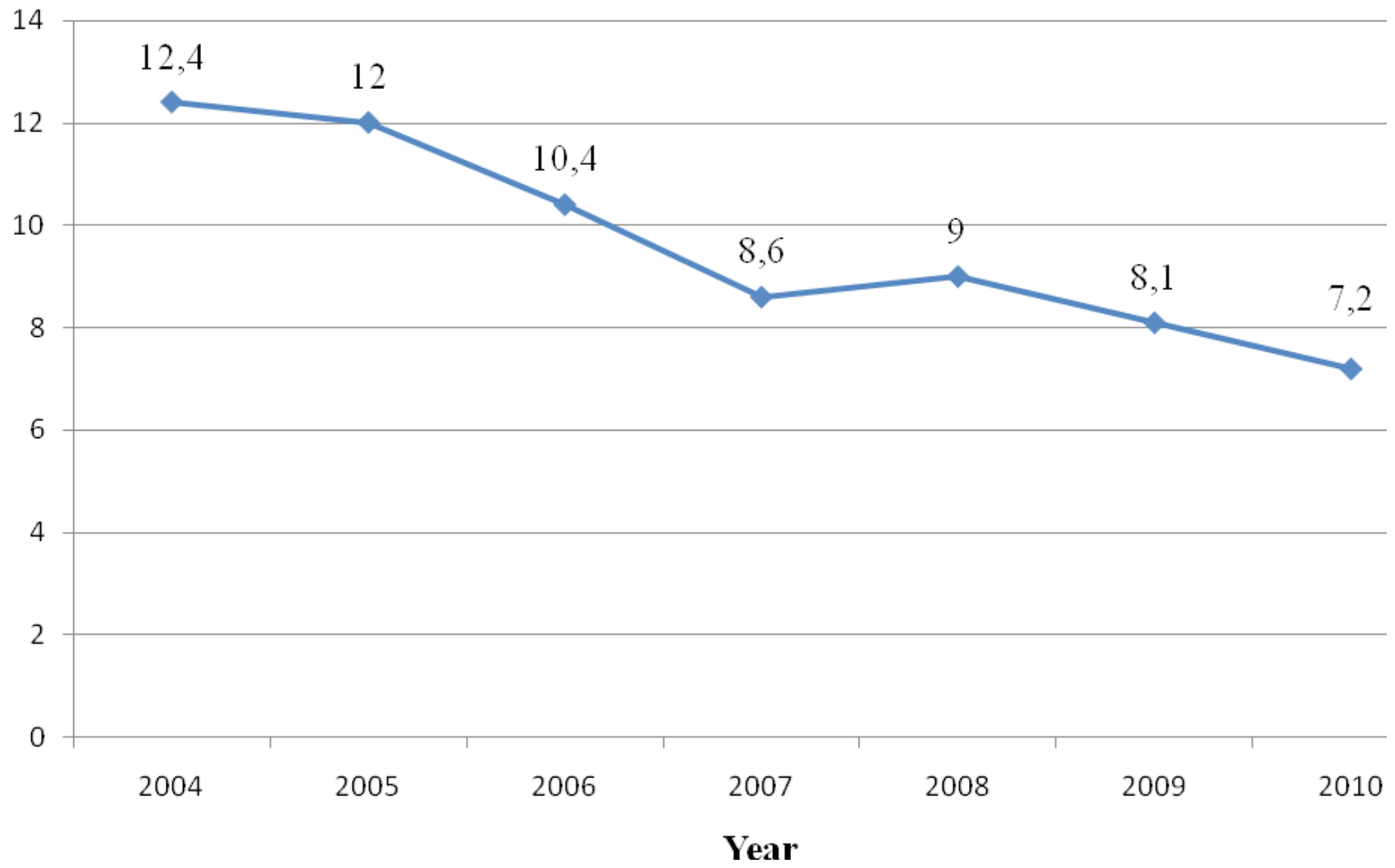

Figure 3: Evolution of hospital neonatal mortality from 2004 to 2010

As concerns the trends in the causes of the deaths, we noted that congenital malformations were the most deadly, all through the study period; mortality from prematurity was on the decrease, whereas asphyxia and neonatal infections maintained comparatively low but constant frequencies all through (Figure 4). 


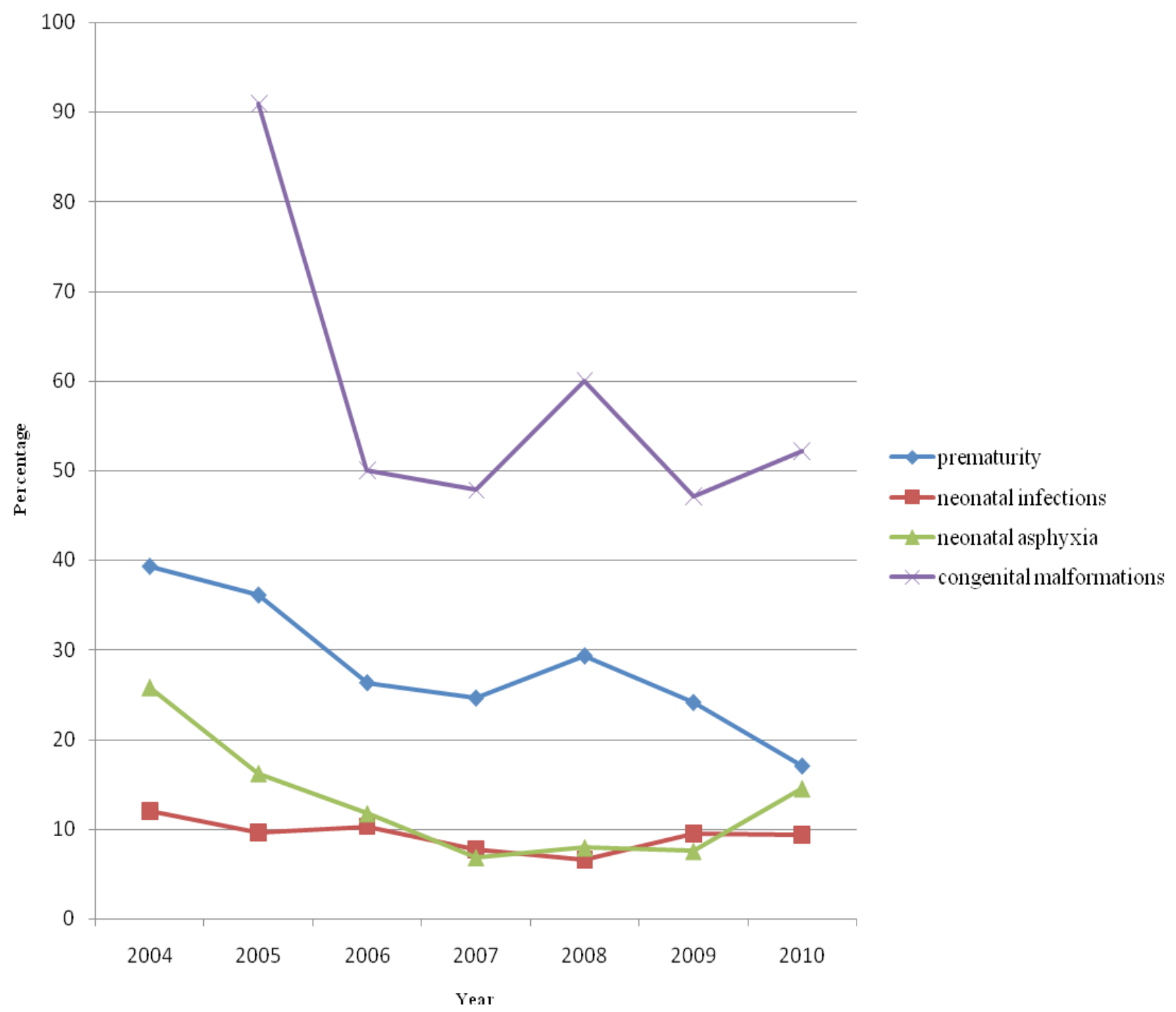

Figure 4. Evolution of mortality due to the principal pathologies from 2004 to 2010.

\section{Discussion}

The overall 10\% hospital neonatal mortality over the seven year period was much lower than the $30.8 \%$ rate recorded by Oladokun et al in Ibadan in $200{ }^{8}$, 20.5\% recorded by Tietche et al in Yaounde in 1992 9 , and the $17.3 \%$ recorded by Eloundou in the same Hospital in $2006{ }^{10}$. But this was much higher than the $2.25 \%$ recorded by Ekure et al in Lagos in $2005^{11}$. However, Ekure's study involved only in-borns, while the other studies including ours involved both in-borns and out-borns.

The majority of the dead babies were of the male sex with a sex ratio of 1.27 . Haon et al, and Ndiaye et al had similar results respectively 1.05 and $1.2^{12,13}$. These authors found that the male sex was a risk factor for neonatal mortality unlike Chaman et al who did not find any significant difference in mortality rates in both sexes ${ }^{14}$.

Neonatal mortality was highest in mothers less than 30years of age . Other authors observed that mortality was highest in neonates from mothers younger than 19 years and older than 35years ${ }^{14,15,16,17}$. The reasons for the difference are not very clear. In our study $70 \%$ of the women were single mothers. These results are in line with those obtained by Eloundou ${ }^{10}$. It can be hypothesized that the presence of a partner brings along financial, psychological and physical support to an expectant mother and her child. This could be a possible explanation for the more deaths of babies from single mothers. It was noticed that 
amongst all deceased neonates $74.2 \%$ were delivered of women from poorly followed- up pregnancies. This suggests that inadequate follow up of pregnancies is largely responsible for neonatal deaths. Our findings are in line with those of other studies ${ }^{15,16}$. The irregular or poor follow up of pregnancies could be due to financial difficulties or simply ignorance and negligence on the part of these women. However it is thought that poverty directly contributes to neonatal mortality translated by the inability to carry out prenatal screening tests, necessary prophylactic measures and attend prenatal clinics.

The neonatal mortality from our study steadily dropped over the years from $12.4 \%$ in 2004 to $7.2 \%$ in 2010. Balaka et al described increasing early neonatal mortality rates in the University Teaching Hospital in Lome Togo from $34,6 \%$ in $1981-1982$ to $60,5 \%$ in 1991-1992 ${ }^{15}$, and the evolution has been irregular in the University Teaching Hospital in Dakar ranging from $21.8 \%$ to $42 \%{ }^{18}$. The steady drop in the mortality rate in our study could be attributed to improvement of the working conditions (increase in the number of personnel and working materials) and regular refresher courses for the personnel of the neonatology unit. The decrease could also be attributed to the fact that there is a minimum package of laboratory investigations for which the parents of the babies pay only on discharge from the hospital. This facilitates investigations (samples are taken from sick neonates and sent to the laboratory analysis, even if the parents are unable to pay on admission), and improves management of the sick neonates.

Most of the neonates $(74.2 \%)$ died during the early neonatal period. Tietche et al at the Yaounde Central Hospital recorded similar rates $81.49 \%$ during the early neonatal period. Authors in other countries found even higher early neonatal mortality rates of up to $91 \%{ }^{9,16,18}$. Thirty five percent of these early neonatal deaths occurred on the first day of life. Our results fall in line with WHO figures which stand between 25 and $45 \%$. These results show that the early neonatal period as the most critical period in the life of a neonate. This is the period of extra uterine adaptation during which the neonate is most likely to develop complications. This therefore implies that neonatal care should be intensified during the first week of life if neonatal mortality is to be significantly reduced.

Neonatal infection was the principal direct cause of neonatal mortality in this hospital with a rate of $38.42 \%$. Tietche et al in Cameroon, ${ }^{9}$ and Azoumah et al in Togo, ${ }^{19}$ found similar rates but ours was higher than those from other African authors ranging from $9 \%$ to $23.5 \% 18,20,21,22$. This is a signal for rigorous hygiene during the prenatal period, delivery and post natal periods for any reduction in infections to be achieved. Prematurity was the second cause of death in our series. Our results show that, neonates with birth weights lower than $2.5 \mathrm{~kg}$ and a gestational age of less than 37 weeks had a much higher mortality rate than those born at term with normal weights. Eloundou and BobossiSerengbe, ${ }^{10,20}$ had similar results with $38.9 \%$ and $30.7 \%$ mortality rates respectively. Many other African researchers have recorded rates ranging from $26 \%$ to $38.9 \%,{ }^{8,11,21,22}$ the highest rate $(52.9 \%)$ was reported by Diallo ${ }^{17}$. Low birth weight and prematurity have been identified as risk factors for neonatal mortality by many other researchers $9,11,12,21,23,24$. Mendes et al in Brazil $^{25}$ found that preterm neonates were fifty times more at risk of dying than term neonates. Satoshi et al in Japan ${ }^{26}$ and Velaphi et al in South Africa ${ }^{27}$ found that low birth weight was a risk factor for mortality. The premature neonate has multiple organ immaturity and therefore faced with difficulties in adaptation to extra uterine life; this coupled with the poor living and working conditions in our country expose the fragile neonate fatal complications like hypothermia, digestive intolerance, infections, bleeding etc..

Neonatal asphyxia was the third most common cause of death in this study. This was contrary to the results obtained by Diallo et al, Tietche et al and Bobossi et $\mathrm{al}^{8,}$ 9,20 who found asphyxia as the second cause of death after infections. The lower incidence of asphyxia in our series, could be the result of improved management of labour, delivery and early referrals of high-risk pregnancies, from the various refresher courses given to personnel in the delivery room in this context.

This hospital has more incubators than any other hospital in Yaounde and therefore receives premature neonates from all over the region, with most of them arriving in critical states due to poor and inadequate means of transportation. This can probably account for the increased deaths of preterms in this study.

Congenital malformations were responsible for $10.54 \%$ of all neonatal deaths in this hospital. Some authors observed lower rates ${ }^{16,18}$. The main congenital malformations were digestive tract malformations, spina bifida and abdominal wall defects. The very large number of malformations is thought to be due to the fact that the pediatric surgery unit of the hospital attracts referrals from all over the country, and most often late referrals making management more complicated. There is also insufficiency in trained staff in neonatal 
resuscitation and adequate surgical equipment to handle difficult cases. This further worsened the prognosis of neonates with congenital malformation needing immediate surgery.

\section{Conclusion}

Neonatal mortality rate in this health facility has registered a steady decrease from 2004 to 2010. Neonatal sepsis, prematurity, birth asphyxia and congenital malformations were the major causes of neonatal deaths. Health education to pregnant women on adequate follow up of pregnancies should be reinforced. Health personnel in the delivery room and in the neonatology unit should be continuously trained on the management and prevention of the most frequent causes of deaths in this context, especially neonatal sepsis. The hospital technical platform needs to be reinforced in both material and human resources to manage complex cases with malformations.

\section{Conflict of interest:}

None

\section{References}

1. United Nations. The Millennium Development Goals Report 2005. New York 2005.

2. Organisation Mondiale de la Santé. Il faut améliorer les soins aux nouveau-nés pour réduire la mortalité infantile. 2010: disponible sur www.who.int. (Accesed 11th November 2010).

3. Fonds des Nations Unies pour l'Enfance (UNICEF). La situation des enfants dans le monde 2009-La santé maternelle et néonatale. New York (NY): UNICEF; 2008.

4. WHO, Perinatal mortality: A listing of available information 1996; WHO/FRH/MSM/96.7. p1-4.

5. Wise PH. Infant mortality/neonatal disease in sexual and reproductive health: A public health perspective; Elservier INC, 2008: p200-2006.

6. Institut National de la Statistique (INS) et ORC Macro 2004. Enquête Démographique et de Santé du Cameroun 2004. Calverton Maryland, USA : INS et ORC Macro.

7. Institut National de la Statistique (INS) et Macro 2011. Enquête Démographique et de Santé et Indicateurs Multiples, EDS-MICS Cameroun, 2011.

8. Oladokun RE, Orimadegun AE, Olodou JA. A ten year review of neonatal deaaths in the special care baby unit at the university college hospital, Ibadan. Niger J Ped 2004,31(4)119-125.

9. Tietche F, Kago I, Njimoke A, Mbonda E, Ndombo PK, Tetanye E. Mortalité hospitalière des nouveau-nés eutrophiques à terme à Yaoundé (Cameroun): Aspects étiologiques.

Méd Afr Noire 1998; 45: 193-195.

10. Eloundou OE. Etiologies et facteurs aggravant la morbidité et la mortalité néonatales à l'Hopital GynécoObstétrique et Pédiatrique de Yaoundé (HGOPY). Thèse de Médecine Faculté de Médecine et de Sciences Biomédicales-Université de Yaoundé I 2007.

11. Ekure EN, Ezeaka VC, Iroha EO, Egri-Okwaji MTC. Neonatal mortality of In-borns in the neonatal unit of a tertiary centre in Lagos, Nigeria. Nig Quart J Hosp Med 2005, 15(2):55-58.

12. Haon PT, Bao TV, Phong DN, Huong NT, Lazare M, Boelaert M. Mortalité néonatale précoce à l'Hopital de gynécologie-obstétrique de Hanoi,Vietnam. Bull Soc Pathol Exot 2000; 93: 62-65.

13. Ndiaye O, Sall G, Diagne I, Diouf S, Kuakuvi N. morbidité et mortalité néonatales au centre hospitalier Abass Ndao de Dakar (Senegal). Arch Pediatr 2001; 8: 1019-1022.

14. Chaman R, Naieni KH, Golestan B, Nabavizadeh H, Yunesian M. Neonatal mortality risk factors in a rural part of Iran: a nested case-control study. Iran J Publ Health 2009; 38: 48-52.

15. Balaka B, Agbere A, Kpemissi E, Baeta S, Kessie K, Assimadi K. Evolution de la mortalité neonatale précoce en dix ans (1981-82 \& 1991-92) au CHU de lome : quelle politique de santé néonatale pour demain ? Méd Afr Noire 1998; 45: 430-434.

16. Diallo S, Kourouma S, Camara Y. Mortalité neonatale à l'institut de nutrition et de santé de l'enfant (INSE). Méd Afr Noire 1998; 45: 326-329.

17. World Health Organisation. Neonatal and Perinatal Mortality: Country, regional and global estimates 2004. WHO library cataloguing-in-publication data 2007.

18. Cissé CT, Yacoubou Y, Ndiaye O, Diop-Mbengue R, Moreau J-C. Evolution de la mortalité néonatale précoce entre 1994 et 2003 au CHU de Dakar. J Gynecol Obstet Biol Reprod 2006; 35: 46-52.

19. Azoumah KD, Balaka B, Aboubakari AS, Matey $\mathrm{K}$, Youlou A, Agbere AD. Morbidité et mortalité néonatales au CHU Kara (Togo). Méd Afr Noire 2010; 57: 109-112.

20 Bobossi-serengbe G, Deyamissi TSS, Diemer HC, A.Gaudueille, G.Gresenguet, Mandaba JL, et al. Morbidité et mortalité néonatales au complexe 
pédiatrique de Bangui (Centrafrique).

Méd Afr Noire 2004; 5103: 159-163.

21. Simiyu. DE morbidity and mortality of neonates admitted in general pediatric wards at the Kenyatta national hospital. E Afr Med J 2003; 80 (12):661-6

22. Ogunlesi TA, Ogufowora OB, Adekanmbi AF, Fetuga MB, Runsewe-Abiodun TL, Oyundeyi MM. Neonatal mortality at the Olabussi Onabanjo Hospital Sagamu. Niger J Ped 2006; 33(2) 40-46.

23. Djadou K-E, Azouma D, Yable G, Dakey G, Sanda P, Dokounor D, et al. Mortalité néonatale au centre hospitalier régional de Tsévié (Togo). Arch Pediatr 2006; 13: 1156-1159

24. Monebenimp F, Tchiro R, Nana AD. Morbidité et mortalité des naissances intra-hospitalières du Centre Hospitalier Universitaire de Yaoundé, Cameroun. Clin Mother Child Heath 2005; 2: 355-358.

25. Mendes KG, AnselmoOlinto MT, DiasdaCosta JS. Case- control study on infant mortality in Southern Brazil. Rev Saúde Pública 2006;40(2):240-248

26. Satoshi K, Masanori F, Izumi S, Hiofumi A, Kazuhiko K, Yasufumi $\mathrm{H}$ et al. Morbidity and mortality of infants with very low birth weight in Japan: Center variation. Pediatrics 2006; 118; 1130.

27. Velaphi SC, Mokhachane M, Mphahlele RM, BeckhArnold E, Kuwanda ML, Cooper PA. Survival of very low birh weight infants according to birth weight and gestational age in a public hospital. S Afr Med J 2005; 95: 504-509. 